\title{
Research on the Impact and Mechanism for the Inhibition of Micrococcus Catalase Activity by Typical Tetracyclines
}

\author{
Luyao Ren, Qian Wang, Yonggang Du, Pengju Xu, and Wansong Zong \\ College of Geography and Environment, Shandong Normal University, 1\# Daxue Road, Jinan, Shandong 250014, China \\ Correspondence should be addressed to Wansong Zong; wansongzong@hotmail.com
}

Received 30 May 2020; Revised 16 September 2020; Accepted 26 September 2020; Published 23 October 2020

Academic Editor: Maxim P. Evstigneev

Copyright (c) 2020 Luyao Ren et al. This is an open access article distributed under the Creative Commons Attribution License, which permits unrestricted use, distribution, and reproduction in any medium, provided the original work is properly cited.

\begin{abstract}
As potential inhibitors target to biological enzymes, antibiotics may have certain impacts on the biochemical treatment process. With micrococcus catalase (CAT) served as the target molecule, the impact and inhibition mechanism for typical tetracyclines (TCs) were evaluated. Toxicity experiments showed that TCs had significant inhibition on CAT in the sequence of tetracycline $>$ chlortetracycline $>$ oxytetracycline $>$ doxycycline. To clarify the inhibition mechanism between TCs and CAT which was explored with the assistance of fluorescence spectroscopy and MOE molecule simulation. According to fluorescence analysis, TCs quenched the fluorescence signal of CAT by the mode of static quenching. Combined with toxicity data, it could be presumed that TCs combined with the catalytic active center and thus inhibited CAT. Above presumption was further verified by the molecular simulation data. When TCs combined with the catalytic center of CAT, the compounds have increased combination areas and prominent energy change (compared with the compounds formed by TCs and noncatalytic center recommend by MOE software). IBM SPSS statistics showed that TC toxicity positively correlated with the hydrogen bonds such as $\mathrm{O}^{13} \rightarrow \mathrm{Glu}_{252}, \mathrm{O}^{1} \leftarrow \mathrm{Arg}_{195}$, and $\mathrm{O}^{6} \rightarrow \mathrm{Asp}_{249}$, but negatively correlated with the hydrogen bonds such as $\mathrm{O}^{10} \rightarrow \mathrm{Pro}_{363}$, $\mathrm{O}^{10} \rightarrow \mathrm{Lys}_{455}$, and $\mathrm{O}^{12} \rightarrow \mathrm{Asn}_{127}$. TC toxicity also positively correlated with the ion bonds ofN ${ }^{4}-\mathrm{Glu}_{252}$, but negatively correlated with the ion bonds of $\mathrm{N}^{4}-\mathrm{Asp}_{379}$. Hydrogen bonds and ion bonds for above key sites were closely related to the inhibition effect of TCs on CAT.
\end{abstract}

\section{Introduction}

TCs have been widely used in animal husbandry and aquaculture as the advantages of low-cost and broad antibacterial spectrum [1-4]. Because of their low bioavailability [5], 50\%$80 \%$ of TCs enter the environment as contaminants without being metabolized [6]. Residual antibiotics have posed serious threat to environment $[7,8]$. In addition, the abuse of antibiotics leads to the emergence of numerous drugresistant pathogens [9]. Drug residues and related resistance genes have attracted the attention of international environmental scholars $[10,11]$.

In view of TC biotoxicity, controls on their levels become of great importance. At present, the main treatment methods are the chemical method and biochemical method [12-14]. Compared with the chemical method, the biochemical method has the advantages of low-cost and easy engineering, thus has become the mainstream technology [15]. However, the biochemical method has the problems of difficult microbial domestication and not impact resistance [16, 17]. As potential inhibitors of biological enzymes, antibiotics have certain impacts on the biochemical treatment process. Accordingly, evaluating the inhibition effect of antibiotics on biological enzymes is necessary $[17,18]$.

Biological enzymes include hydrolases, oxidoreductases, and transferases, which are mainly derived from bacteria, fungi, protozoa, and algae. Catalase (CAT) is an oxidoreductase with iron porphyrin as a prosthetic group $[19,20]$. It promotes the decomposition of $\mathrm{H}_{2} \mathrm{O}_{2}$ into molecular oxygen and water, removes hydrogen peroxide from the body, and protects cells from $\mathrm{H}_{2} \mathrm{O}_{2}$ toxicity $[20,21]$. It is one of the key enzymes in the biological defense system and plays an important role in the biochemical treatment of TC wastewater [22]. And the CAT activity directly reflects the biological activity of the treatment system and affects the whole sewage treatment process once inhibited [16, 17]. Therefore, 


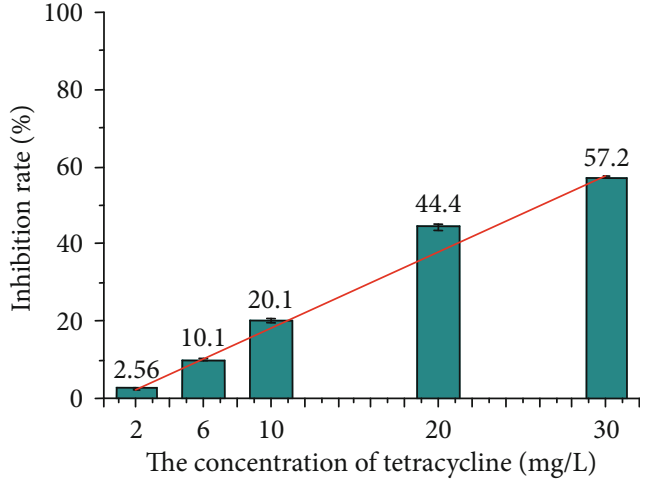

(a)

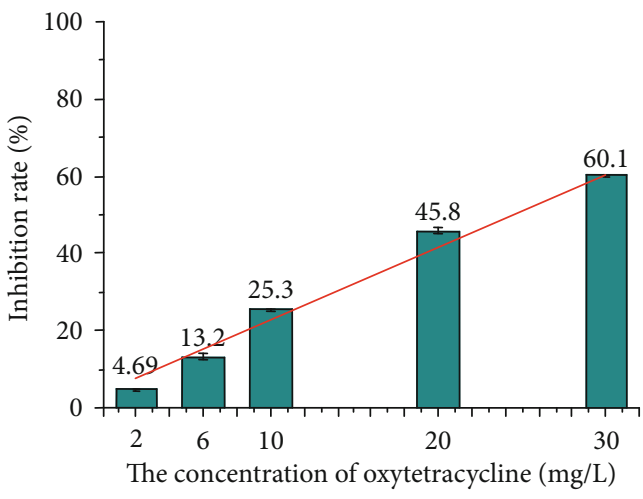

(c)

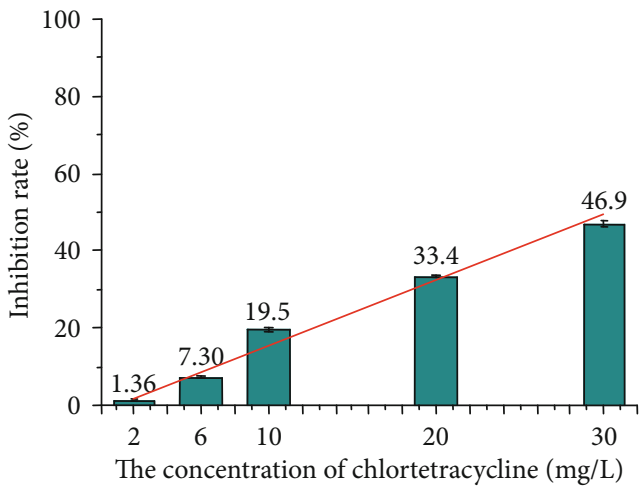

(b)

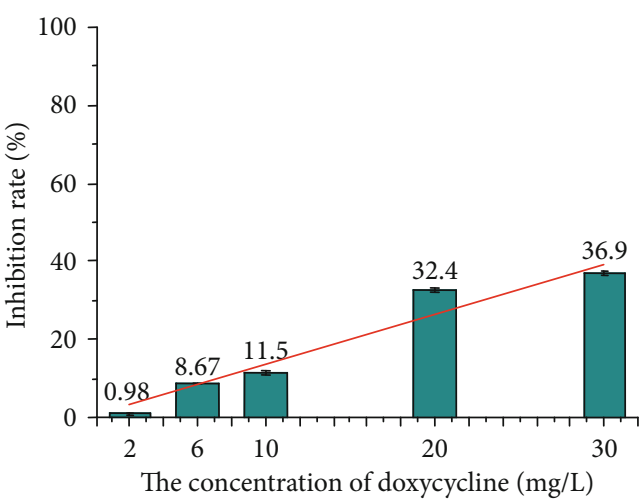

(d)

FIgURE 1: Inhibition effect of typical TC target to the CAT activity: (a) tetracycline, (b) chlortetracycline, (c) oxytetracycline, and (d)doxycycline.

clarifying the impact and inhibition mechanism of TCs on the CAT activity not only helps to understand the discrepant toxicity of TCs but also has practical guiding significance for engineering measures to solve TC pollution.

To clarify the inhibition mechanism, micrococcus catalase was selected to evaluate the impact and inhibition mechanism by typical TCs. The interaction between TCs and CAT was explored with the assistance of fluorescence spectroscopy and molecular docking simulation. According to fluorescence spectroscopy, the impact of TCs on CAT characteristic fluorescence spectra could be obtained to confirm their quenching mechanism. In addition, the inhibition mechanism could be explained by the docking data: combination area, energy change, hydrogen bonds, and ion bonds for key sites. This study offers a comprehensive cognition on TC toxicity regulation and provides valid theoretical support to control their potential risk.

\section{Materials and Methods}

2.1. Materials. Tetracycline, chlortetracycline, oxytetracycline, and doxycycline were purchased from Meilun Biotechnology Co., Ltd. (Dalian, China). Micrococcus CAT was purchased from Sigma (Saint-Quentin Fallavier, France). Hydrochloric acid, sulfuric acid, sodium hydroxide, $\mathrm{H}_{2} \mathrm{O}_{2}$, sodium dihydrogen phosphate, and disodium phosphate were purchased from Sinopharm (Shanghai, China). Metha- nol and ethanol were obtained from Fisher Chemicals (Fair Lawn, NJ, USA).

2.2. Toxicity Test for the Interaction between TCs and CAT. Referring to Yang's ultraviolet spectrophotometry [23], the biological toxicity of TC target to CAT was evaluated. $2 \mathrm{~mL}$ of $0.2 \mathrm{~mol} / \mathrm{L}$ phosphate buffer ( $\mathrm{pH} 7.8$ ), $1 \mathrm{ml}$ of $400 \mathrm{mg} / \mathrm{L}$ CAT solution, different amounts $(100 \mathrm{mg} / \mathrm{L}-1500 \mathrm{mg} / \mathrm{L})$ of TC solution, and $5 \mathrm{~mL}$ of $0.3 \% \mathrm{H}_{2} \mathrm{O}_{2}$ were sequentially added to $50 \mathrm{~mL}$ centrifuge tubes. Tetracycline was solubilized with ethanol, chlortetracycline was solubilized with methanol, oxytetracycline was solubilized with $0.2 \mathrm{~mol} / \mathrm{L}$ hydrochloric acid solution, and doxycycline was solubilized with $0.1 \mathrm{~mol} / \mathrm{L}$ sodium hydroxide solution. After shaking for 20minutes, sulfuric acid was added immediately and then measured at $240 \mathrm{~nm}$ by UV spectrophotometer. The toxicity of TCs on CAT was reflected by measuring the absorbance of the remaining $\mathrm{H}_{2} \mathrm{O}_{2}$. The toxicity of TCs was calculated by the formula of $\mathrm{A}_{\text {sample }}-\mathrm{A}_{\text {control }}$. $\mathrm{A}_{\text {control }}$ and $\mathrm{A}_{\text {sample }}$ were the absorbance of the reference sample (without TCs) and test sample at $240 \mathrm{~nm}$, respectively.

2.3. Fluorescence Spectroscopy for the Interaction between TCs and CAT. Fluorescence spectra were measured by a threedimensional fluorescence spectrometer (Hiachi Limited, F7000). Firstly, $2 \mathrm{~mL}$ of $0.2 \mathrm{~mol} / \mathrm{L}$ phosphate buffer ( $\mathrm{pH} 7.8$ ), $1 \mathrm{~mL}$ of $400 \mathrm{mg} / \mathrm{L}$ CAT solution, and $1 \mathrm{ml}$ different amounts 


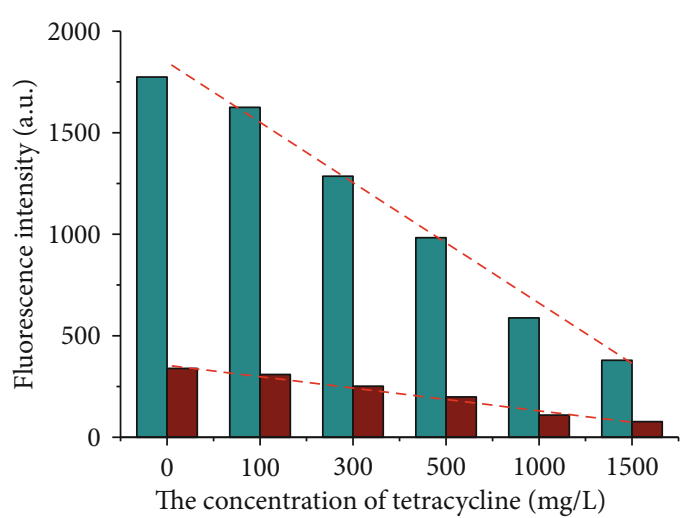

Wavelength: $307.0 \mathrm{~nm}$ Wavelength: $344.4 \mathrm{~nm}$

(a)

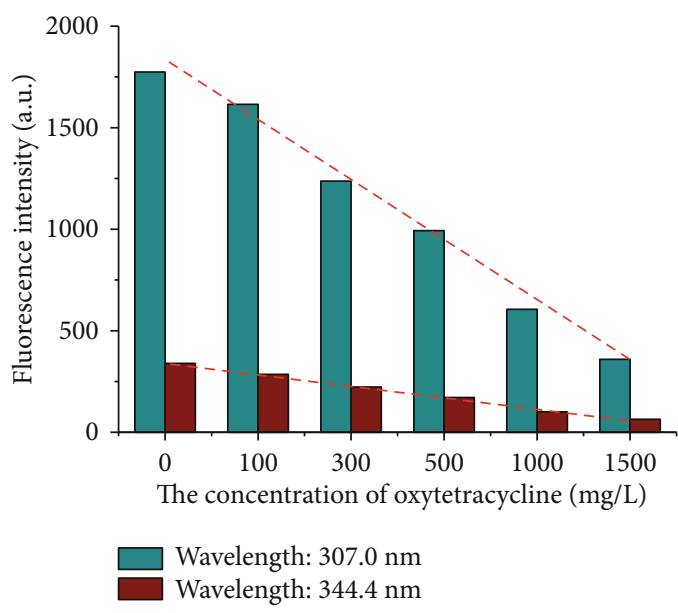

(c)

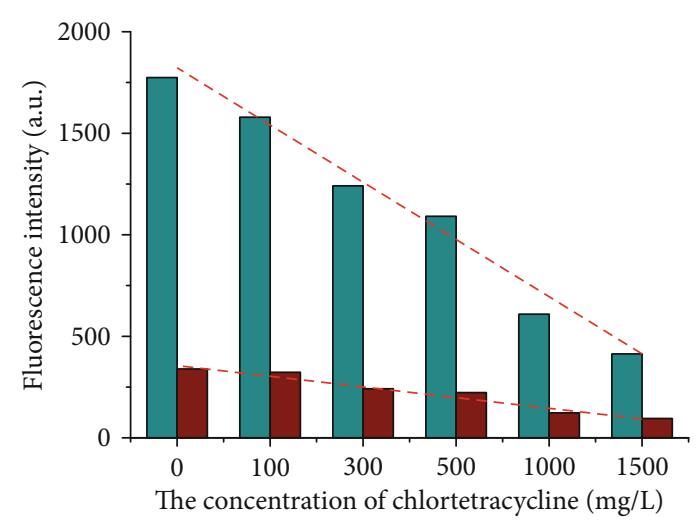

Wavelength: $307.0 \mathrm{~nm}$ Wavelength: $344.4 \mathrm{~nm}$

(b)

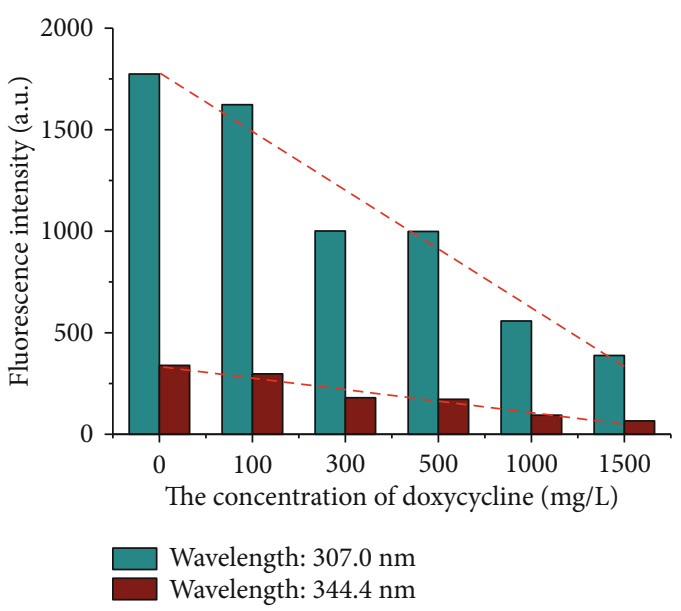

(d)

FIGURE 2: Inhibition effect of different TCs on CAT fluorescence intensity: (a) tetracycline, (b) chlortetracycline, (c) oxytetracycline, and (d) doxycycline.

$(0 \mathrm{mg} / \mathrm{L}-1500 \mathrm{mg} / \mathrm{L})$ of TC solution were sequentially added to $50 \mathrm{~mL}$ colorimetric tubes. In addition, $2 \mathrm{~mL}$ of $0.2 \mathrm{~mol} / \mathrm{L}$ phosphate buffer (pH 7.8) and $1 \mathrm{~mL}$ of $1500 \mathrm{mg} / \mathrm{L}$ TC solution were added to another $50 \mathrm{~mL}$ colorimetric tube, then make the final volume to $50 \mathrm{ml}$ with ultra-pure water, and mixed and kept for $30 \mathrm{~min}$. The fluorescence spectra of samples were measured at an excitation wavelength of $276 \mathrm{~nm}$ and an emission wavelength range of 287-380 $\mathrm{nm}$. Fluorescence quenching type was calculated by the dynamic quenching formula of Stern-Volmer: $F_{0} / F=1+$ $K_{\text {sv }}[Q]=1+K_{q} \tau_{0}[Q][24] . F_{0}$ and $F$ were the fluorescence intensity in the absence and presence of the quencher. $K_{\mathrm{sv}}$, [Q], $K_{q}$, and $\tau_{0}$ were the quenching constant, the concentration of the quencher, the fluorescence quenching rate constant, and the average lifetime of the fluorescent molecules in the absence of the quencher. For biomacromolecules, $\tau_{0}=10^{-8} \mathrm{~s}$.

2.4. Molecular Simulation for the Interaction between TCs and CAT. Molecular docking simulation was performed with Molecular Operating Environment software (MOE, version
16.09). The main experimental steps are as follows: the model forCAT was obtained from the Protein Data Bank (PDB code 1HBZ, http://www.rcsb.org/pdb/home/home.do) [25]. Then, receptor CAT was minimized for energy optimization. MOE parameters were set as follows: amber10 EHT, solvation $\mathrm{r}$ field, temperature $25.0^{\circ} \mathrm{C}, \mathrm{pH} 7.4$, and salinity $0.05 \mathrm{M}$. The interactions between TCs and CAT (combination areas, energy change, hydrogen bonds, and ion bonds for main interaction sites) were simulated by the "molecular hole method" to clarify the molecular mechanism for the discrepant inhibition of TCs on CAT. The detailed operating procedures can be found in supplementary information.

\section{Results and Discussions}

3.1. Biological Toxicity Evaluation of TC target to CAT. CAT catalyzes the decomposition of $\mathrm{H}_{2} \mathrm{O}_{2}$ into oxygen and water. Therefore, the toxicity of TCs on CAT could be reflected by measuring the absorbance of the remaining $\mathrm{H}_{2} \mathrm{O}_{2}$. Figure 1 shows that the activity of CAT was inhibited by TCs in varying degrees. With the increase of TC concentration, the inhibition effect on CAT was on the rise, showing a strong dose- 
TABLE 1: Stern-Volmer quenching constants for the quenching of TCs on CAT at emission wavelengths of $307.0 \mathrm{~nm}$ and $344.4 \mathrm{~nm}$, respectively.

\begin{tabular}{|c|c|c|c|}
\hline TCs & & $K_{q}\left(10^{12} \mathrm{Lmol}^{-1} \mathrm{~s}^{-1}, 307.0 \mathrm{~nm}\right)$ & $K_{q}\left(10^{12} \mathrm{Lmol}^{-1} \mathrm{~s}^{-1}, 344.4 \mathrm{~nm}\right)$ \\
\hline \multirow{5}{*}{ Tetracycline } & $100 \mathrm{mg} / \mathrm{L}$ & 2.04 & 2.19 \\
\hline & $300 \mathrm{mg} / \mathrm{L}$ & 2.81 & 2.59 \\
\hline & $500 \mathrm{mg} / \mathrm{L}$ & 3.58 & 3.15 \\
\hline & $1000 \mathrm{mg} / \mathrm{L}$ & 4.49 & 4.67 \\
\hline & $1500 \mathrm{mg} / \mathrm{L}$ & 5.45 & 5.05 \\
\hline \multirow{5}{*}{ Chlortetracycline } & $100 \mathrm{mg} / \mathrm{L}$ & 2.96 & 1.25 \\
\hline & $300 \mathrm{mg} / \mathrm{L}$ & 3.43 & 3.22 \\
\hline & $500 \mathrm{mg} / \mathrm{L}$ & 3.00 & 2.51 \\
\hline & $1000 \mathrm{mg} / \mathrm{L}$ & 4.58 & 4.23 \\
\hline & $1500 \mathrm{mg} / \mathrm{L}$ & 5.26 & 4.08 \\
\hline \multirow{5}{*}{ Oxytetracycline } & $100 \mathrm{mg} / \mathrm{L}$ & 2.27 & 4.41 \\
\hline & $300 \mathrm{mg} / \mathrm{L}$ & 3.33 & 4.01 \\
\hline & $500 \mathrm{mg} / \mathrm{L}$ & 3.62 & 4.52 \\
\hline & $1000 \mathrm{mg} / \mathrm{L}$ & 4.44 & 5.46 \\
\hline & $1500 \mathrm{mg} / \mathrm{L}$ & 6.05 & 6.63 \\
\hline \multirow{5}{*}{ Doxycycline } & $100 \mathrm{mg} / \mathrm{L}$ & 2.07 & 3.16 \\
\hline & $300 \mathrm{mg} / \mathrm{L}$ & 5.72 & 6.57 \\
\hline & $500 \mathrm{mg} / \mathrm{L}$ & 3.45 & 4.32 \\
\hline & $1000 \mathrm{mg} / \mathrm{L}$ & 4.85 & 5.81 \\
\hline & $1500 \mathrm{mg} / \mathrm{L}$ & 5.30 & 6.18 \\
\hline
\end{tabular}

effect relationship. Based on the slope of linear fitting between inhibition rate and TC concentration, the toxicity of TCs on CAT could be obtained in the sequence of tetracycline $>$ oxytetracycline $>$ chlortetracycline $>$ doxycycline.

Accordingly, specific inhibition mechanisms and interspecies discrepancies about the interaction between TCs and CAT deserved further attention.

3.2. The Fluorescence Intensity Effect of TC Target to CAT. Fluorescence spectroscopy can be to study the interaction between proteins and small molecules. When TCs interact with CAT, the fluorescence intensity of CAT will show a dose-effect relationship with TC concentration [26]. To explore the interaction mechanism, the fluorescence spectrum of CAT (with or without TCs) was obtained. Figure S1 shows the inhibition effect of tetracycline (served as an example) on the fluorescence spectra of CAT. The fluorescence intensity of CAT with TC concentration was plotted to intuitively evaluate (excitation wavelength: $276 \mathrm{~nm}$, emission wavelengths: $307.0 \mathrm{~nm}$ and $344.4 \mathrm{~nm}$, respectively, see Figure 2). With the increasing concentration of TCs, the fluorescence intensity of CAT showed a significant decrease trend. In addition, the interaction was assumed to be dynamic quenching and then calculated by the dynamic quenching formula of Stern-Volmer: $F_{0} / F=1+K_{\text {sv }}[Q]=1+K_{q} \tau_{0}[Q]$ [24]. The collision quenching constant due to the maximum diffusion control of biomacromolecules by various quenchers was $2.0 \times 10^{10} \mathrm{Lmol}^{-1} \mathrm{~s}^{-1}$. Since quenching constants in Table 1 were much larger than above $K_{q}$, the fluorescence quenching of TCs on CAT was caused by static quenching with complexes formed. Combined with toxicity data, the activity of CAT was inhibited to different degrees by TCs, so it was preliminarily judged that TCs and CAT were static quenching in catalytic active center.

\subsection{The Discrepant Molecular Mechanism for the Interaction between TCs and CAT}

3.3.1. The Interaction Models for TC-CAT Complexes. Based on the toxicity experiment and fluorescence spectroscopy experiment, the interaction for TCs to CAT could be preliminary explained, but the specific molecular mechanism was not clarified. According to molecular docking simulation, the interaction models between TCs and CAT could be obtained, and the discrepant inhibition mechanism could be clarified.

CAT is a binding enzyme with iron porphyrin as a prosthetic group in the catalytic active center. The stereoscopic structure model for CAT was obtained from the Protein Data Bank (PDB code 1HBZ, catalase from micrococcus lysodeikticu http://www.rcsb.org/pdb/home/home.do) [25]. Based on the molecular hole method of MOE software, the interaction models between TCs and CAT in the iron porphyrin catalytic active center and no-catalytic active center were obtained (see Figure 3, with tetracycline-CAT served as the example). Noncatalytic active center was the largest likelihood combination center recommended by software (Compute-Site Finder...-Apply-Select the largest likelihood combination center-Dummies-Yes-Close). Besides, the ligand interaction diagram could provide the specific interaction sites between TCs and CAT (see Figure S2, the order of each atomic 


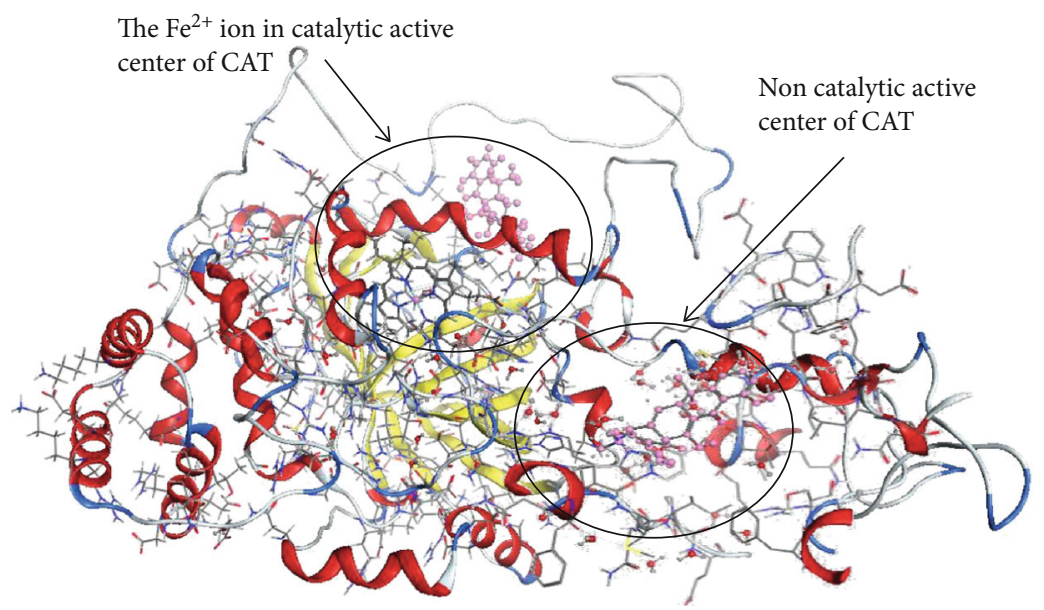

FIgURE 3: The stereoscopic interaction structure model for TC-CAT complexes (with tetracycline-CAT complexes served as the example).

TABLE 2: Combination area ratio and energy change for TC-CAT complexes at different combination sites.

\begin{tabular}{|c|c|c|c|c|c|}
\hline TCs & $\begin{array}{c}\text { Combination area ratio } \\
\text { for catalytic active } \\
\text { center }\end{array}$ & $\begin{array}{l}\text { Combination area ratio } \\
\text { for noncatalytic active } \\
\text { center }\end{array}$ & $\begin{array}{l}\text { Energy change for } \\
\text { catalytic active center } \\
(\mathrm{kcal} / \mathrm{mol})\end{array}$ & $\begin{array}{c}\text { Energy change for } \\
\text { noncatalytic active center } \\
(\mathrm{kcal} / \mathrm{mol})\end{array}$ & $\begin{array}{l}\text { Combination } \\
\text { sites }\end{array}$ \\
\hline Tetracycline & $58 \%$ & $53 \%$ & $|-5.9784|$ & $|-3.2641|$ & \multirow{4}{*}{$\begin{array}{c}\text { Catalytic } \\
\text { active center }\end{array}$} \\
\hline Chlortetracycline & $62 \%$ & $57 \%$ & $|-7.9117|$ & $|-4.8341|$ & \\
\hline Oxytetracycline & $58 \%$ & $56 \%$ & $|-6.9473|$ & $|-4.5725|$ & \\
\hline Doxycycline & $55 \%$ & $53 \%$ & $|-3.5510|$ & $|-3.3425|$ & \\
\hline
\end{tabular}

name was automatically sorted by software). Accordingly, combination areas and energy changes for different TCCAT complexes, the hydrogen bonds, and ion bonds for key sites could also be obtained. By comparing on the correlation for changed parameters with toxicity, the discrepant molecule mechanism of TCs on CAT could be clarified.

3.4. Combination Areas and Energy Changes For different TC-CAT Complexes. The interaction between TCs and CAT usually involved in changed combination area and energy. To further clarify the combination site, relevant parameters were obtained by MOE, and the rate of combination areas to small molecule areas and energy changes for TC-CAT complexes at different combinatiolizan sites were calculated (see Table 2). Combination area ratio and energy change in the catalytic active center of CAT were higher than those in the noncatalytic active center. Therefore, TCs interacted with CAT the in catalytic active center.

Based on data in the catalytic activity center, the combination area ratio for different TC-CAT complexes was determined as follows: chlortetracycline $>$ tetracycline $=$ oxytetracycline $>$ doxycycline. Besides, the energy change in the catalytic active center for different TCs combined with CAT had different decreased in the sequence of chlortetracycline $>$ oxytetracycline $>$ tetracycline $>$ doxycycline. Combined with toxicity data, combination area ratio and energy change were not well correlated with TC toxicity. The combination area and energy change of chlortetracycline were the largest, which could be

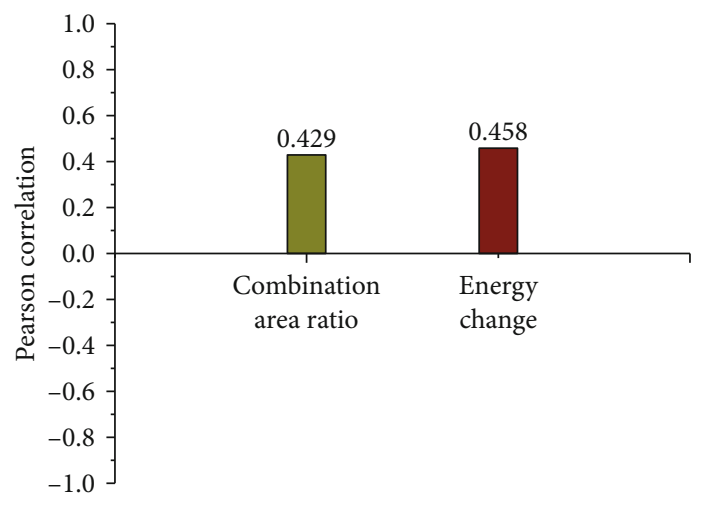

FIgURE 4: The correlation between TC toxicity and combination area ratio/energy change in the catalytic active center.

related to its special chlorine atom structure. Furthermore, the correlation between TC toxicity and combination area ratio/energy change was evaluated by IBM SPSS statistics (see Figure 4). The results showed that the combination area ratio and energy change were basically positively correlated with TC toxicity. Accordingly, it could be served as the reference indexes to evaluate the interaction of TCs on CAT.

3.5. The Hydrogen Bonds for Different TC-CAT Complexes. The specific interaction sites between TCs and CAT can be seen through the ligand interaction diagram provided by the MOE software (see Figure 5). Accordingly, combination 


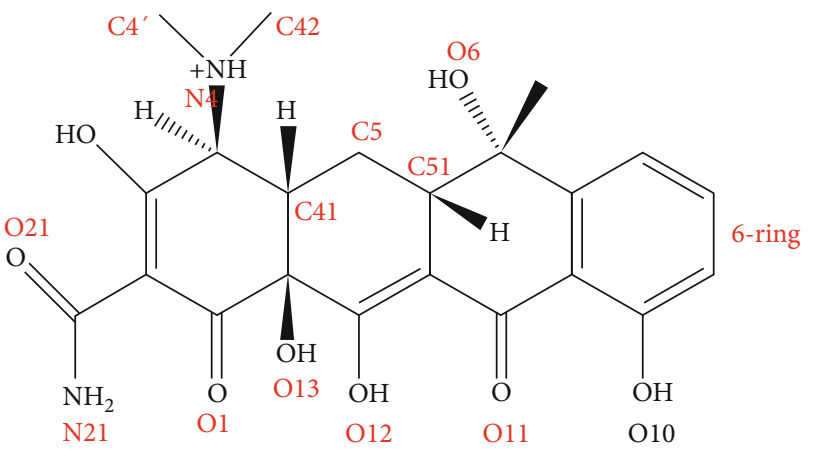

(a)

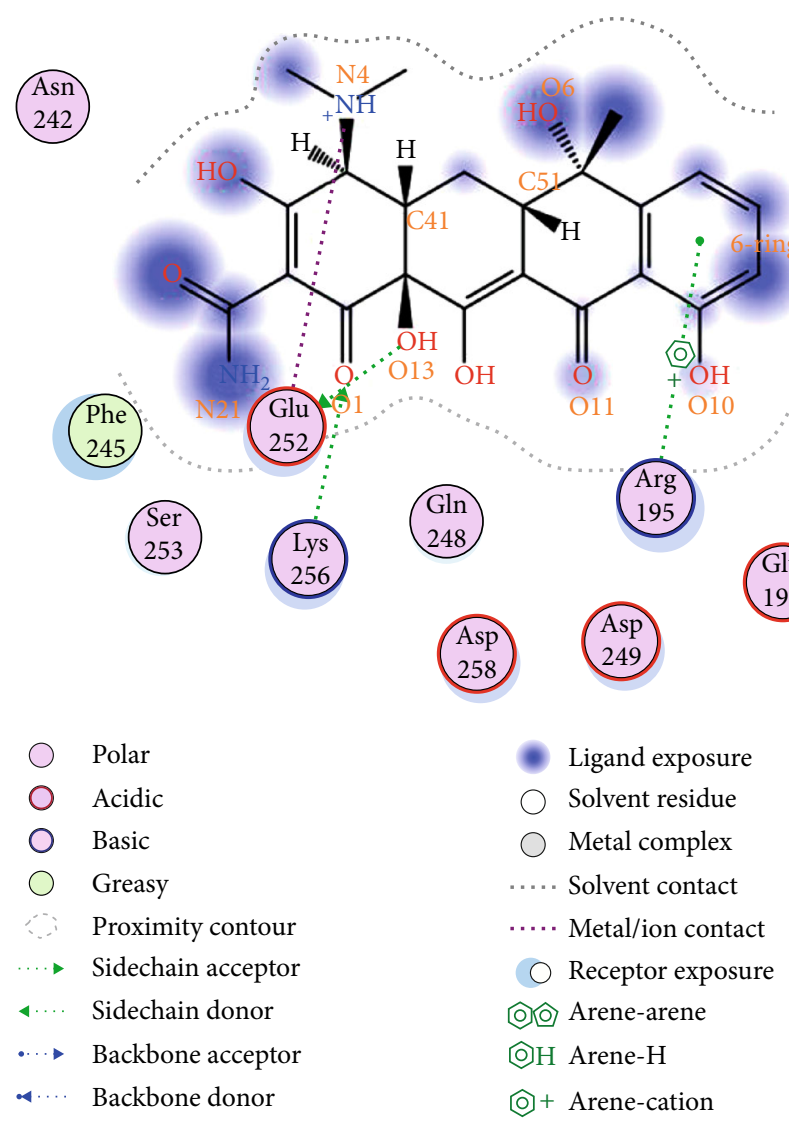

(b)

FIgURE 5: The general structure and the ligand interaction diagram: (a)the general structure of TCs; (b) The ligand interaction diagram between tetracycline and CAT (with one of them as an example, the order of each atomic name was automatically sorted by software).

areas and energy changes for different TC-CAT complexes, the hydrogen bonds, and ion bonds for key sites could also be obtained. By comparing on the correlation for changed parameters with toxicity, the discrepant molecule mechanism of TCs on CAT could be clarified.

Simulation information of the hydrogen bonds for TCCAT complexes was shown in Figure 6(a).The total hydrogen bonds for different TC-CAT complexes were determined as follows: chlortetracycline $>$ tetracycline $>$ doxycycline $>$ oxytetracycline. Combined with toxicity data, the downward trend for total hydrogen bonds was not well correlated with the decreased toxicity of TCs. As TCs had multiple potential hydrogen bonding sites with CAT, the hydrogen bonds for single interaction sites were also obtained. Different TCs interacted with CAT to form discrepant hydrogen bonds with different strength. Accordingly, the hydrogen bonds were also important factors to cause the discrepant inhibition effect of TCs on CAT.

To clarify the discrepant inhibition effect, the correlation between TC toxicity and hydrogen bonds for main interaction sites was further evaluated by IBM SPSS statistics. Figure 6(b) shows that TC toxicity was positively correlated with the hydrogen bonds of $\mathrm{O}^{13} \rightarrow \mathrm{Glu}_{252}, \mathrm{O}^{1} \leftarrow \operatorname{Arg}_{195}$, $\mathrm{O}^{6} \rightarrow \mathrm{Asp}_{249}, \quad \mathrm{O}^{10} \rightarrow \mathrm{Glu}_{252}, \quad \mathrm{O}^{1} \leftarrow \mathrm{Lys}_{256}, \quad$ 6-ring-Arg 195, $\mathrm{N}^{21} \rightarrow \mathrm{His}_{368}, \mathrm{O}^{11} \leftarrow \mathrm{Asn}_{127}, \mathrm{C}^{41} \rightarrow \mathrm{Asp}_{379}, \mathrm{C}^{51} \rightarrow \mathrm{Asp}_{379}, \quad 6-$ ring-Gln $357, \quad \mathrm{O}^{6} \rightarrow \mathrm{Asn}_{369}, \quad \mathrm{O} 6 \leftarrow \mathrm{His}_{368}, \quad \mathrm{O}^{11} \leftarrow \mathrm{Asn}_{369}$, 


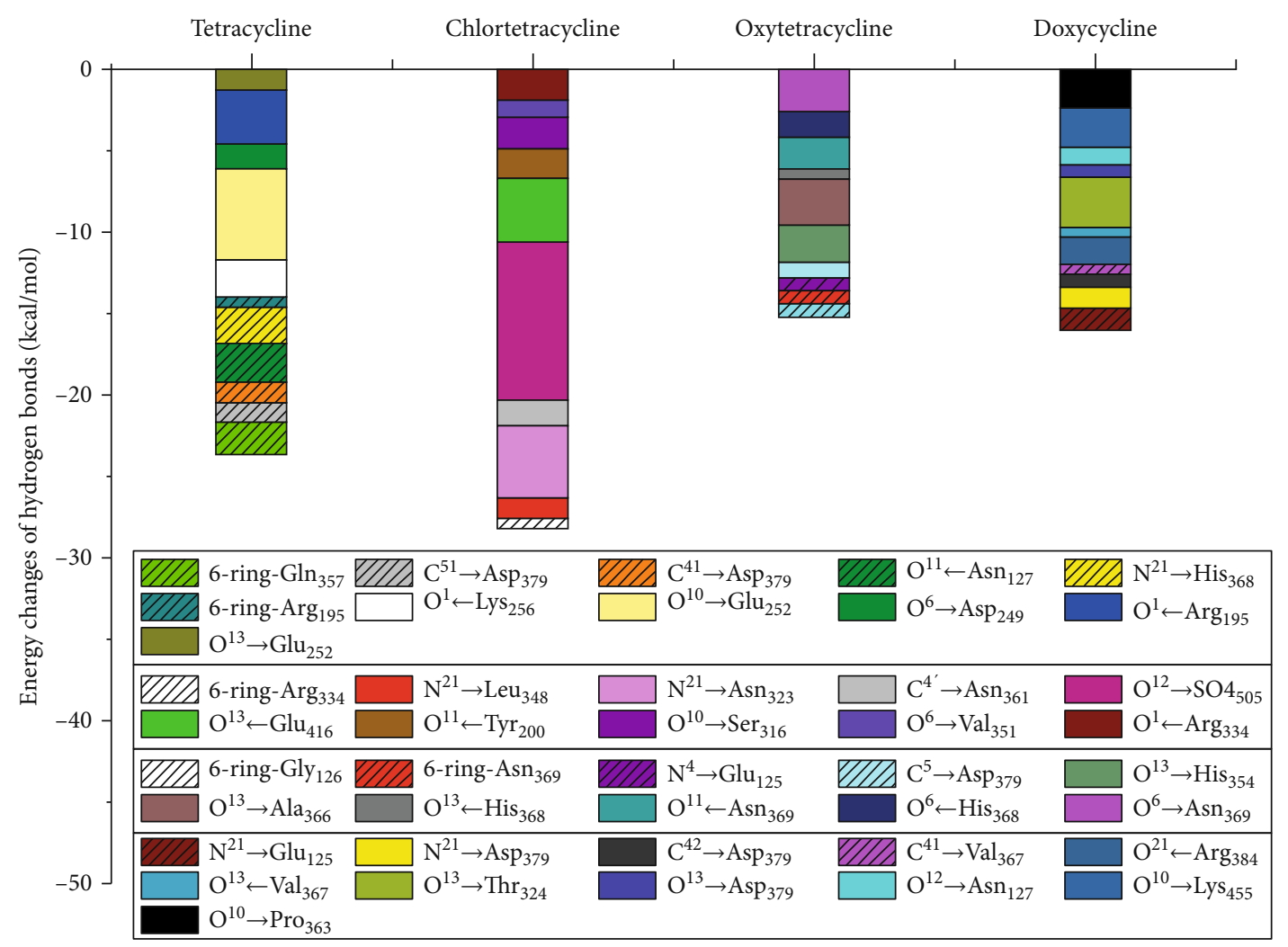

(a)
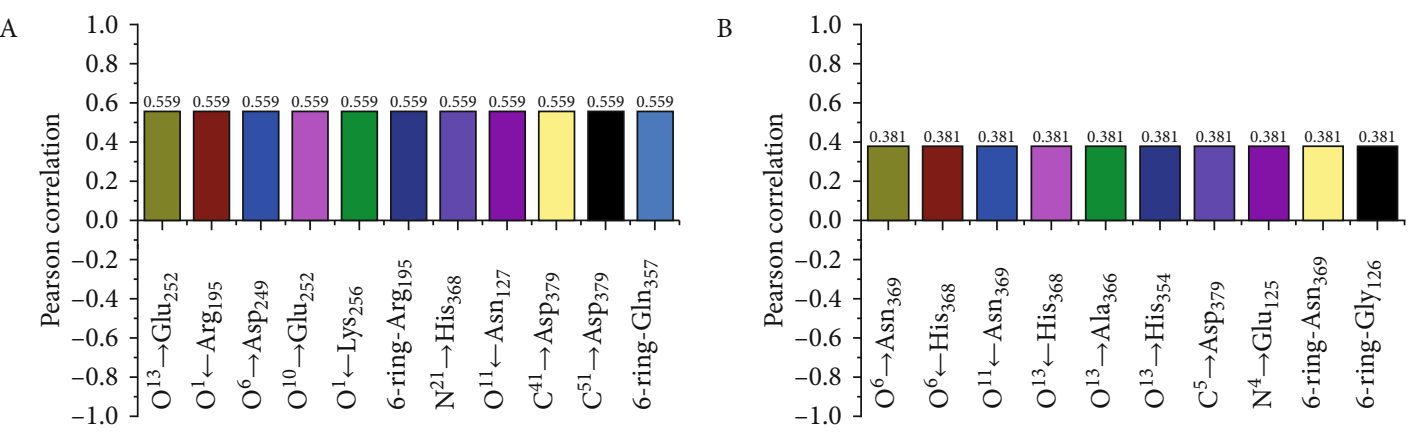

C
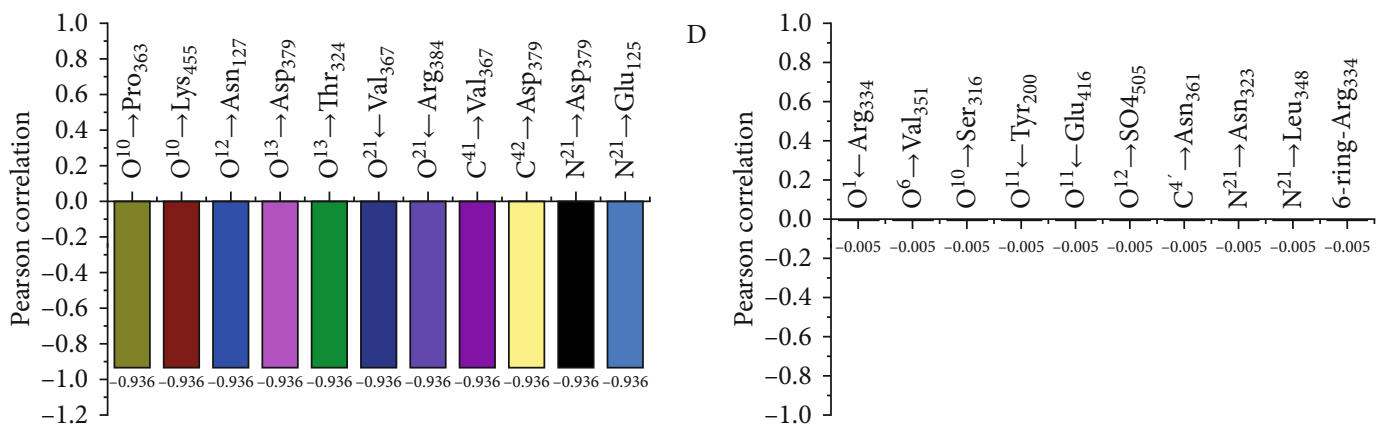

(b)

Figure 6: Molecular simulation information of the hydrogen bonds for TC-CAT complexes: (a) energy changes of the hydrogen bonds for TC-CAT complexes. (b) The correlation between TC toxicity and hydrogen bonds for main interaction sites: (a) $0.5<$ positive correlation $<1$, (b) $0<$ positive correlation $<0.5$, (c) $-1<$ negative correlation $<-0.5$, and (d) $-0.5<$ negative correlation $<0$.

$\mathrm{O}^{13} \leftarrow \mathrm{His}_{368}, \quad \mathrm{C}^{5} \rightarrow \mathrm{Asp}_{379}, \quad \mathrm{~N}^{4} \rightarrow \mathrm{Glu}_{125}, \quad \mathrm{O}^{13} \rightarrow \mathrm{Ala}_{366}$, $\mathrm{O}^{13} \rightarrow \mathrm{His}_{354}$, 6-ring-Asn ${ }_{369}$, and 6-ring-Gly ${ }_{126}$, but negatively correlated with $\mathrm{O}^{10} \rightarrow \mathrm{PrO}_{363}, \quad \mathrm{O}^{10} \rightarrow \mathrm{Lys}_{455}$,
$\mathrm{O}^{12} \rightarrow \mathrm{Asn}_{127}, \quad \mathrm{O}^{13} \rightarrow \mathrm{Asp}_{379}, \quad \mathrm{O}^{13} \rightarrow \mathrm{Thr}_{324}, \quad \mathrm{O}^{13} \leftarrow \mathrm{Val}_{367}$, $\mathrm{O}^{21} \leftarrow \operatorname{Arg}_{384}, \mathrm{C}^{41} \rightarrow \mathrm{Val}_{367}, \mathrm{C}^{42} \rightarrow \mathrm{Asp}_{379}, \mathrm{~N}^{21} \rightarrow \mathrm{Asp}_{379}$, and $\mathrm{N}^{21} \rightarrow \mathrm{Glu}_{125}$. By statistical analysis, Figure $7($ a) shows that 


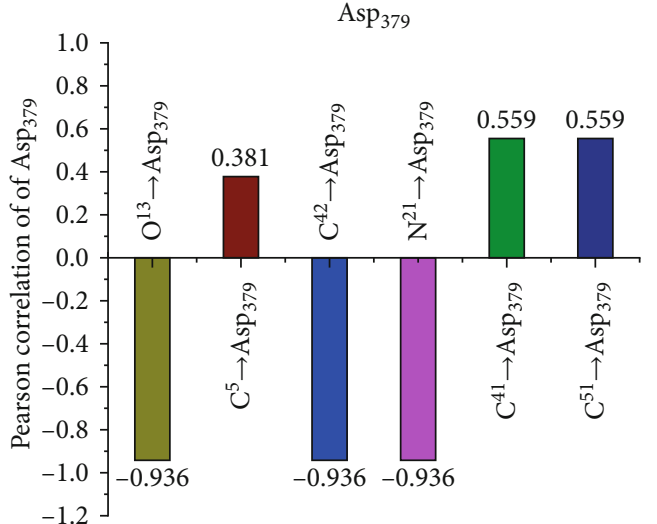

(a)

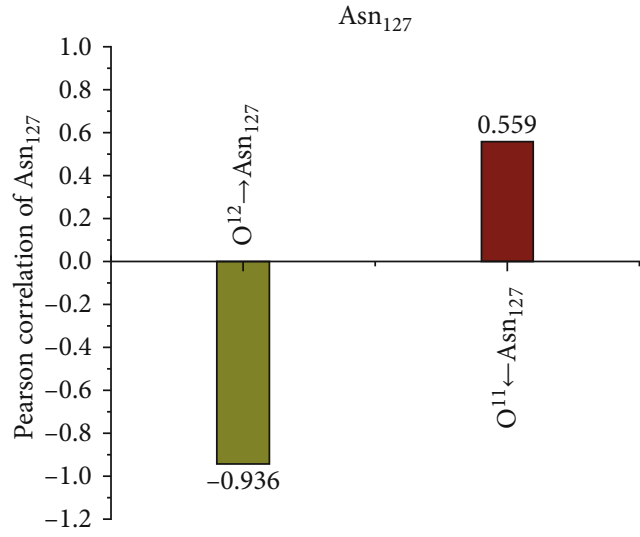

(c)

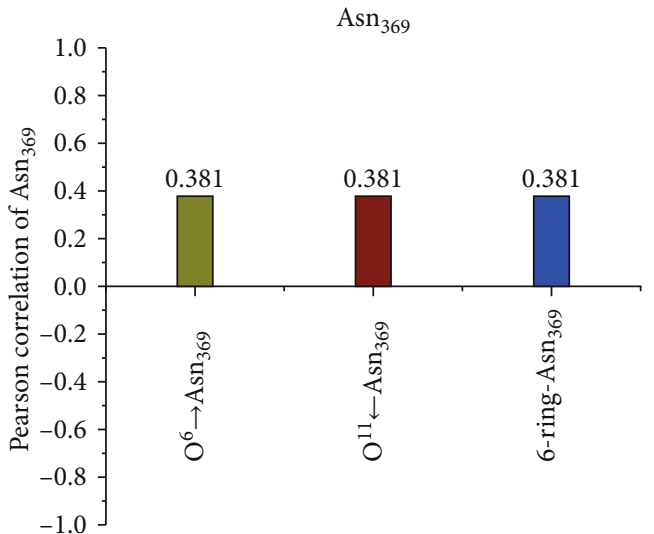

(e)

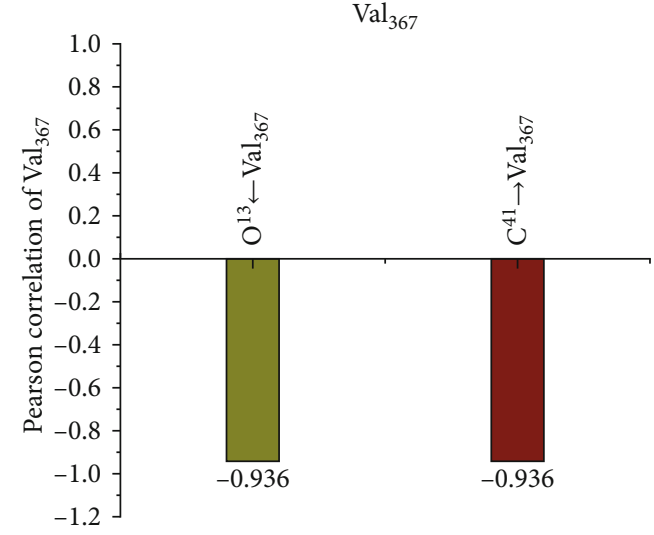

(b)

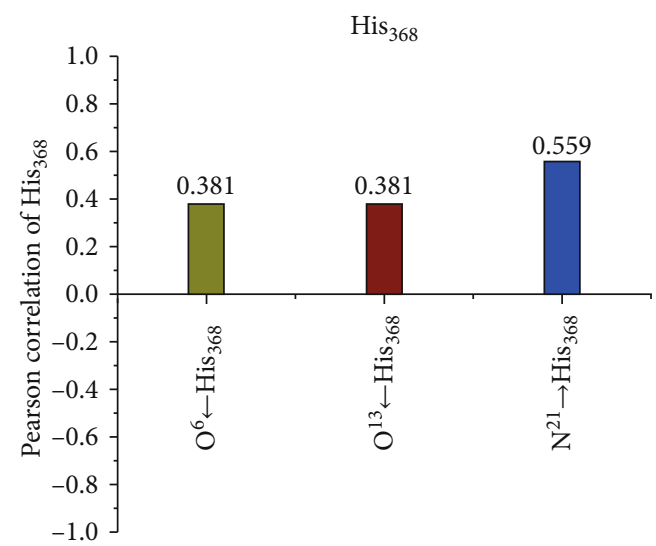

(d)

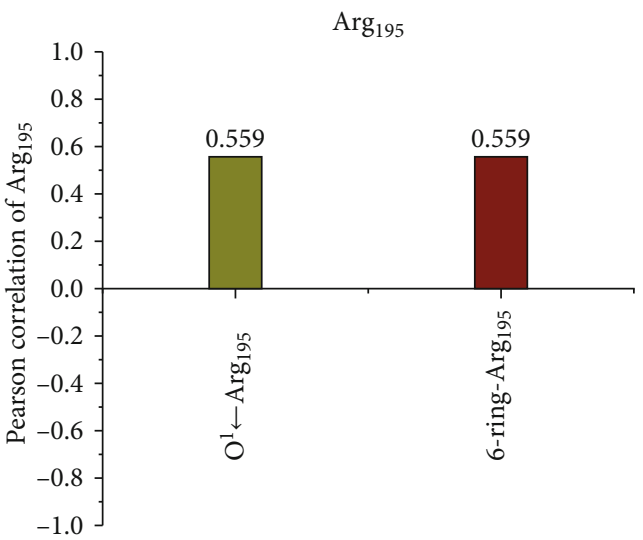

(f)

Figure 7: Continued. 


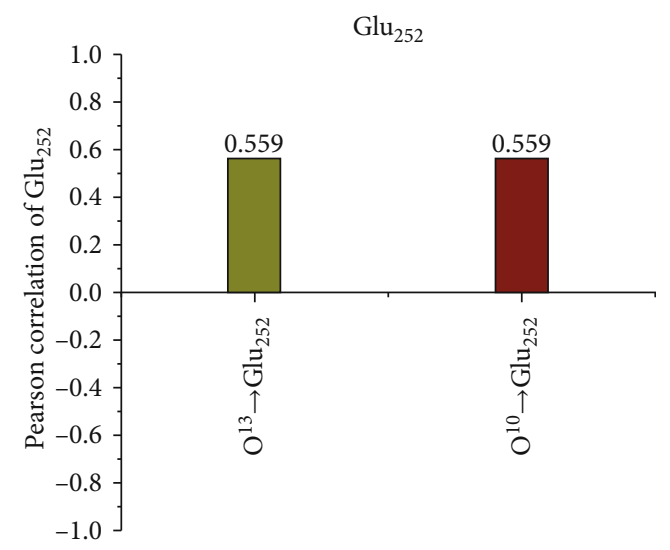

(g)

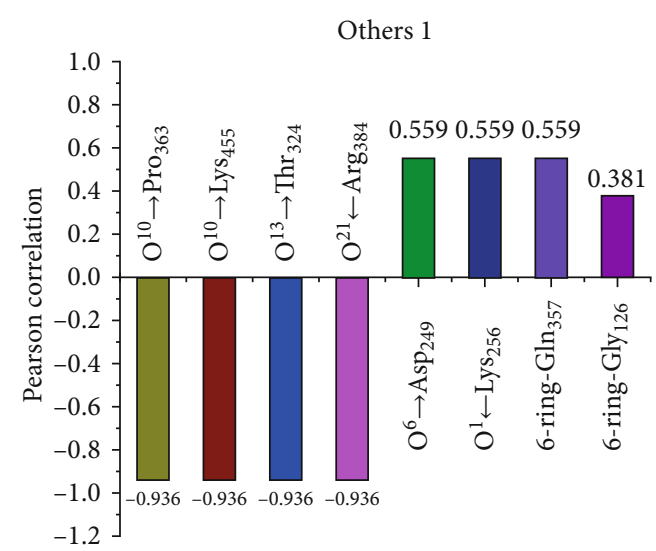

(h)

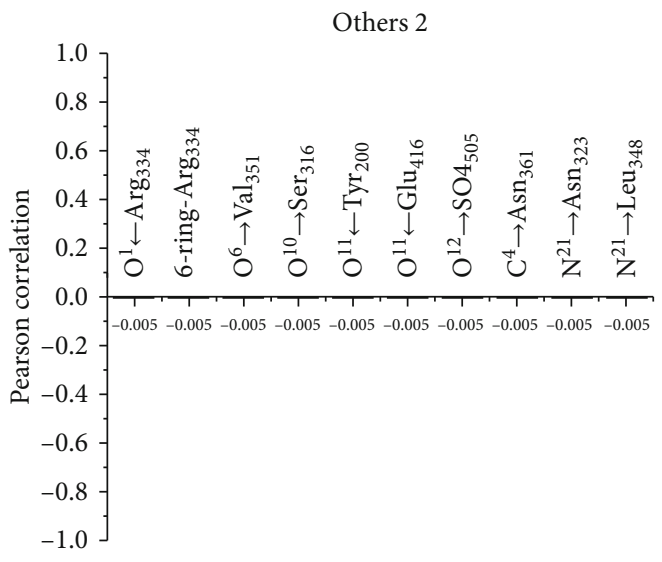

(i)

Figure 7: Pearson correlation between TC toxicity and hydrogen bonds for main interaction sites: (a) Asp $\mathrm{As}_{379},(\mathrm{~b}) \mathrm{Val}_{367},(\mathrm{c}) \mathrm{Asn}_{127},(\mathrm{~d})$ $\mathrm{His}_{368}$, (e) Glu125, (f) $\mathrm{Asn}_{369}$, (g) $\mathrm{Arg}_{195}$, (h) $\mathrm{Glu}_{252}$, and (i) other correlated amino acid residues.

the interaction between TCs and CAT was closely related to $\mathrm{Asp}_{379}$ residues in CAT, including six hydrogen bonds of $\mathrm{C}^{41} \rightarrow \mathrm{Asp}_{379}, \quad \mathrm{C}^{51} \rightarrow \mathrm{Asp}_{379}, \quad \mathrm{O}^{13} \rightarrow \mathrm{Asp}_{379}, \quad \mathrm{C}^{5} \rightarrow \mathrm{Asp}_{379}$ $\mathrm{C}^{42} \rightarrow \mathrm{Asp}_{379}$, abnd $\mathrm{N}^{21} \rightarrow \mathrm{Asp}_{379}$. Besides, the correlation sequence of residues including 2-3 interaction sites was verified as follows (Figures $7(\mathrm{~b})-7(\mathrm{~g})): \mathrm{Val}_{367}\left(\mathrm{O}^{13} \leftarrow \mathrm{Val}_{367}\right.$, $\left.\mathrm{C}^{4 \mathrm{~A}} \rightarrow \mathrm{Val}_{367}\right)>\mathrm{Asn}_{127} \quad\left(\mathrm{O}^{11} \leftarrow \mathrm{Asn}_{127}, \quad \mathrm{O}^{12} \rightarrow \mathrm{Asn}_{127}\right)>\mathrm{His}_{368}$ $\left(\mathrm{O}^{6} \leftarrow \mathrm{His}_{368}, \mathrm{~N}^{21} \rightarrow \mathrm{His}_{368}, \mathrm{O}^{13} \leftarrow \mathrm{His}_{368}\right)>\mathrm{Glu}_{125}\left(\mathrm{~N}^{4} \rightarrow \mathrm{Glu}_{125}\right.$, $\left.\mathrm{N}^{21} \rightarrow \mathrm{Glu}_{125}\right)>\mathrm{Asn}_{369} \quad\left(\mathrm{O}^{6} \rightarrow \mathrm{Asn}_{369}, \quad \mathrm{O}^{11} \leftarrow \mathrm{Asn}_{369}, \quad 6\right.$-ring$\left.\operatorname{Asn}_{369}\right)>\operatorname{Arg} 195 \quad\left(\mathrm{O}^{1} \leftarrow \operatorname{Arg}_{195}, \quad 6\right.$-ring-Arg $\left.{ }_{195}\right)>\mathrm{Glu}_{252}$ $\left(\mathrm{O}^{1 \mathrm{C}} \rightarrow \mathrm{Glu}_{252}, \mathrm{O}^{10} \rightarrow \mathrm{Glu}_{252}\right)$. Figure $7(\mathrm{~h})$ shows that other correlated amino acid residues including only one interaction sites $\left(\mathrm{O}^{6} \rightarrow \mathrm{Asp}_{249}, \mathrm{O}^{1} \leftarrow \mathrm{Lys}_{256}, 6\right.$-ring-Gln ${ }_{357}, \mathrm{O}^{10} \rightarrow \mathrm{PrO}_{363}$, $\left.\mathrm{O}^{10} \rightarrow \mathrm{Lys}_{455}, \mathrm{O}^{13} \rightarrow \mathrm{Thr}_{324}, \mathrm{O}^{21} \leftarrow \mathrm{Arg}_{384}\right)$ were also important parameters to evaluate inhibition mechanism of TCs on CAT. However, Gly ${ }_{126}, \operatorname{Arg}_{334}, \mathrm{Val}_{351}, \mathrm{Ser}_{316}, \mathrm{Tyr}_{200}$, $\mathrm{Glu}_{416}, \mathrm{So}_{505}, \mathrm{Asn}_{361}, \mathrm{Asn}_{323}$, and $\mathrm{Leu}_{348}$ residues were less correlated with TC toxicity (see Figure 7(i)). Combined with the simulation information and related IBM SPSS statistics, changes for above hydrogen bonds could serve as the key indexes to evaluate the interaction of TCs on CAT.

According to statistical analysis, hydrogen bonds related to the key sites of TCs also were ranked (see Figure 8). The interaction between $\mathrm{TCs}$ and CAT was closely related to
$\mathrm{O}^{13}$, involving in hydrogen bonds $\mathrm{O}^{13} \rightarrow \mathrm{Asp}_{379}$, $\mathrm{O}^{13} \rightarrow \mathrm{Thr}_{324}, \mathrm{O}^{13} \leftarrow \mathrm{His}_{368}, \mathrm{O}^{13} \rightarrow \mathrm{Ala}_{366}, \mathrm{O}^{13} \rightarrow \mathrm{His}_{354}$, and $\mathrm{O}^{13} \leftarrow \mathrm{Val}_{367}$. In addition, the correlation sequence of key sites was verified as follows (Figures 8(b)-8(g)): $\mathrm{O}^{10}$ $\left(\mathrm{O}^{10} \rightarrow \mathrm{Ser}_{316}, \mathrm{O}^{10} \rightarrow \mathrm{Glu}_{252}, \mathrm{O}^{10} \rightarrow \mathrm{PrO}_{363}, \mathrm{O}^{10} \rightarrow \mathrm{Lys}_{455}\right)>\mathrm{N}^{21}$ $\left(\mathrm{N}^{21} \rightarrow \mathrm{Asp}_{379}, \quad \mathrm{~N}^{21} \rightarrow \mathrm{Glu}_{125}, \quad \mathrm{~N}^{21} \rightarrow \mathrm{His}_{368}\right.$ ) $>6$-ring (6-ring$\mathrm{Arg}_{195}$, 6-ring-Asn ${ }_{369}$, 6-ring-Arg ${ }_{334}$, 6-ring-Gly 126 , 6-ring$\left.\mathrm{Gln}_{357}\right)>\mathrm{O}^{6} \quad\left(\mathrm{O}^{6} \rightarrow \mathrm{Asn}_{369}, \quad \mathrm{O}^{6} \rightarrow \mathrm{Asp}_{249}, \quad \mathrm{O}^{6} \leftarrow \mathrm{His}_{368}\right.$, $\left.\mathrm{O}^{6} \rightarrow \operatorname{Val}_{351}\right)>\mathrm{O}^{1}\left(\mathrm{O}^{1} \leftarrow \operatorname{Arg}_{334}, \mathrm{O}^{1} \leftarrow \operatorname{Arg}_{195}, \mathrm{O}^{1} \leftarrow \mathrm{Lys}_{256}\right)>\mathrm{O}^{11}$ $\left(\mathrm{O}^{11} \leftarrow \mathrm{Asn}_{369}, \mathrm{O}^{11} \leftarrow \mathrm{Tyr}_{200}, \mathrm{O}^{11} \leftarrow \mathrm{Glu}_{416}, \mathrm{O}^{11} \leftarrow \mathrm{Asn}_{127}\right)>\mathrm{O}^{12}$ $\left(\mathrm{O}^{12} \rightarrow \mathrm{So}_{505}, \mathrm{O}^{12} \rightarrow \mathrm{Asn}_{127}\right)$. Figure 8(i) shows the hydrogen bonds related to only one interaction site of CATs $\left(\mathrm{O}^{21} \leftarrow \mathrm{Arg}_{384}, \quad \mathrm{C}^{4 \mathrm{~A}} \rightarrow \mathrm{Val}_{367}, \quad \mathrm{C}^{42} \rightarrow \mathrm{Asp}_{379}, \quad \mathrm{O}^{1 \mathrm{C}} \rightarrow \mathrm{Glu}_{252}\right.$, $\mathrm{C}^{41} \rightarrow \mathrm{Asp}_{379}, \mathrm{C}^{51} \rightarrow \mathrm{Asp}_{379}, \mathrm{C}^{5} \rightarrow \mathrm{Asp}_{379}, \mathrm{~N}^{4} \rightarrow \mathrm{Glu}_{125}$ ), which also cannot be ignored. Combining MOE simulation information and related IBM SPSS statistics, these closely related hydrogen bond changes can be used as a key indicator to evaluate the interaction between TCs and CAT and are also very important for the regulation of TC toxicity.

3.6. The Ion Bonds for Different TC-CAT Complexes. Simulation information for the ion bonds of TC-CAT complexes were shown in Figure 9(a). Combined with toxicity data, the energy changes of total ion bonds for different TC-CAT 
$\mathrm{O}^{13}$

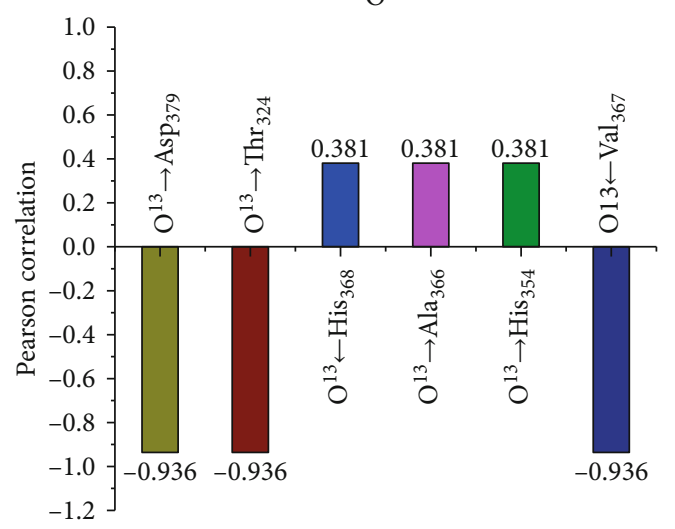

(a)

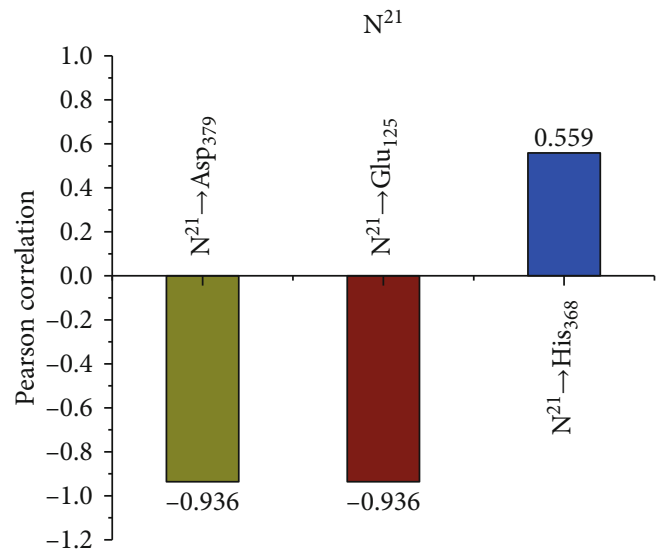

(c)

$\mathrm{O}^{6}$

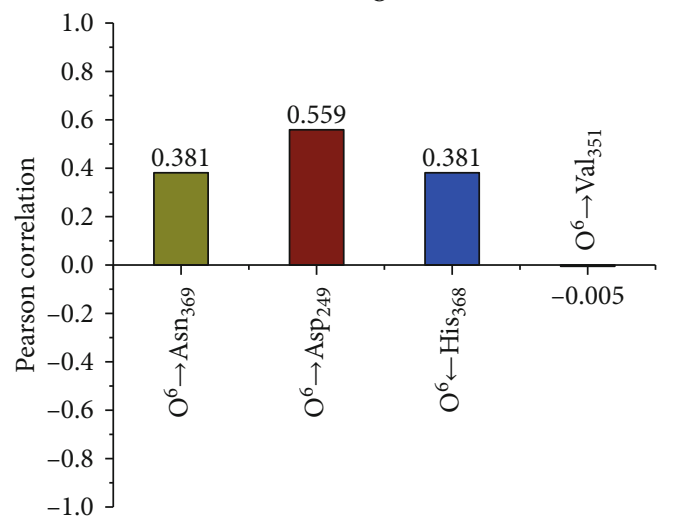

(e)

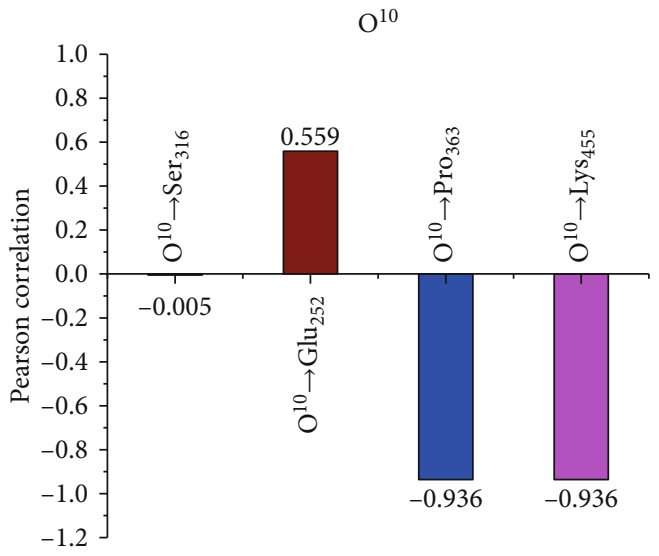

(b)

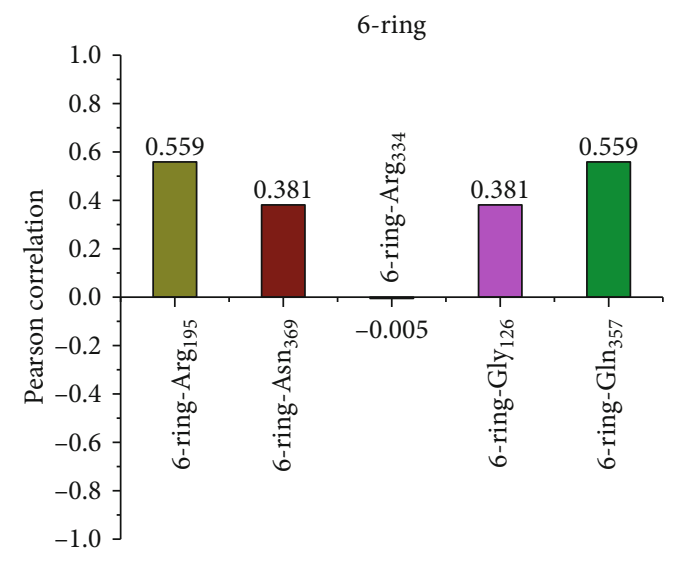

(d)

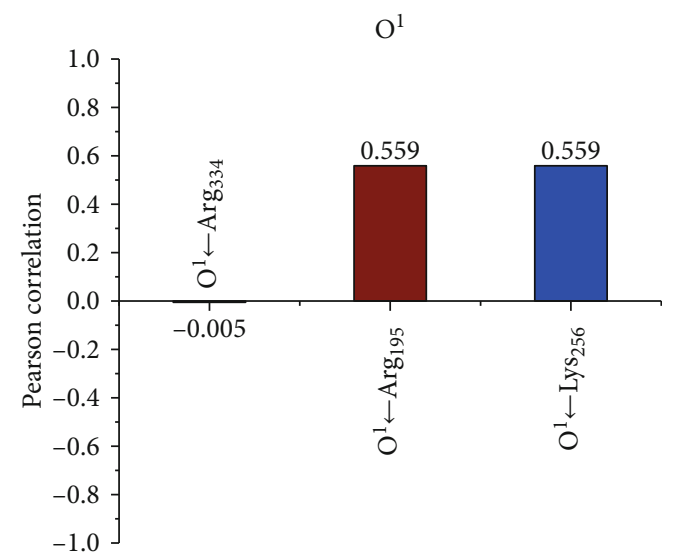

(f)

Figure 8: Continued. 


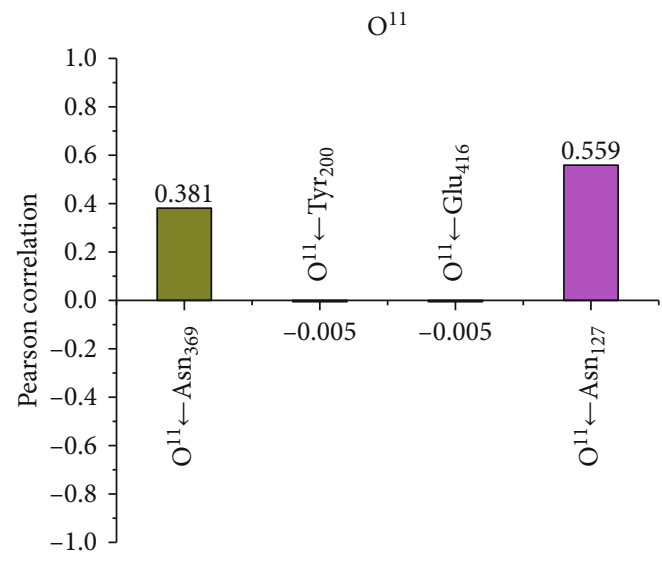

(g)

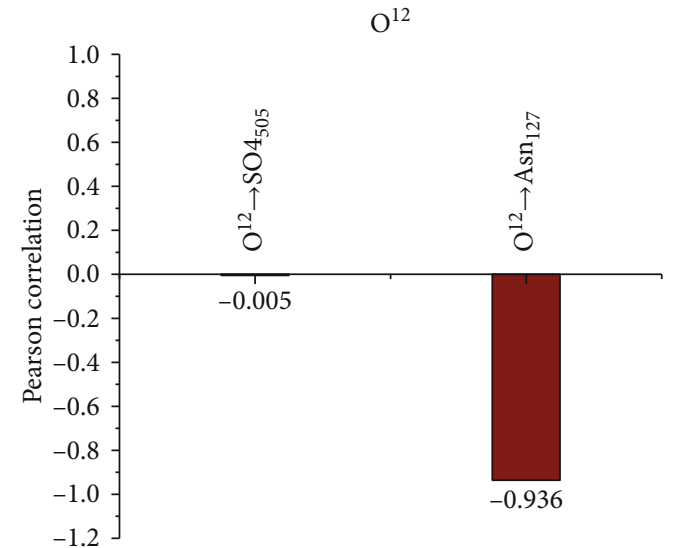

(h)

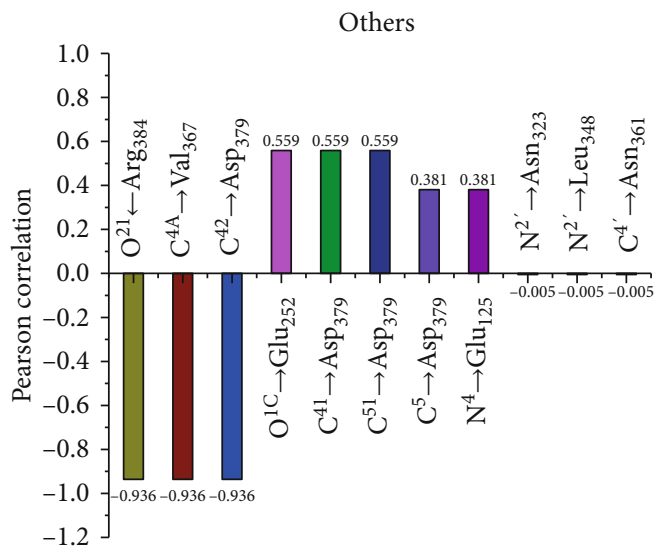

(i)

FIGURE 8: Pearson correlation between TC toxicity and hydrogen bonds for TC main interaction sites: (a) $\mathrm{O}^{13}$, (b) $\mathrm{O}^{10}$, (c) $\mathrm{N}^{21}$, (d) 6-ring, (e) $\mathrm{O}^{6}$, (f) $\mathrm{O}^{1}$, (g) $\mathrm{O}^{11}$, (h) $\mathrm{O}^{12}$, and (i) others.

complexes had no correlation with toxicity. In addition, the ion bonds were all formed by $\mathrm{N}_{4}$ in TCs and amino acids in CAT; therefore, the $\mathrm{N}^{4}$ of the two TCs was important to change the activity of CAT. Furthermore, the correlation between TC toxicity and ion bonds for main interaction sites was evaluated by IBM SPSS statistics. Figure 9(b) shows that the toxicity of TCs was positively correlated with the interaction for $\mathrm{N}^{4}$ with $\mathrm{Glu}_{252}$ residues, but negatively correlated with the interaction for $\mathrm{N}^{4}$ with $\mathrm{Asp}_{379}$ residues. In conclusion, above interactions were not only the key to regulate the toxicity of TCs but also important to keep the activity of CAT.

\section{Conclusions}

To clarify the toxicity inhibition mechanism for the discrepant interaction of TCs on CAT, the toxicity of four typical TCs (tetracycline, chlortetracycline, doxycycline, oxytetracycline) on CAT was evaluated. The inhibition sequence was verified as follows: tetracycline $>$ chlortetracycline $>$ oxytetracycline $>$ doxycycline. With the assistance of fluorescence spectroscopy and MOE molecule simulation, the interactions between TCs and CAT were further evaluated. Fluorescence spectroscopy showed that the reduced fluorescence intensity of CAT should be attributed to static quenching between TCs and CAT in the catalytic active center. Molecular simulation showed that combination sites for TC-CAT complexes were in the catalytic active center by calculating the combination area ratio and energy change in the catalytic active center/noncatalytic active center. Combined with toxicity data, the combination area ratio and energy change in the catalytic active center had basically positive correlation with TC toxicity. In addition, combined with the simulation information and related IBM SPSS statistics, TC toxicity was positively correlated with the hydrogen bonds of $\mathrm{O}^{13} \rightarrow \mathrm{Glu}_{252}$, $\mathrm{O}^{1} \leftarrow \mathrm{Arg}_{195}$, and $\mathrm{O}^{6} \rightarrow \mathrm{Asp}_{249}$, but negatively correlated with $\mathrm{O}^{10} \rightarrow \mathrm{PrO}_{363}, \mathrm{O}^{10} \rightarrow \mathrm{Lys}_{455}$, and $\mathrm{O}^{12} \rightarrow \mathrm{Asn}_{127}$. By statistical analysis, the interaction between TCs and CAT was closely related to $\mathrm{Asp}_{379}, \mathrm{Glu}_{252}, \mathrm{Arg}_{195}, \mathrm{Asn}_{127}, \mathrm{Val}_{367}, \mathrm{His}_{368}$, $\mathrm{Asn}_{369}, \mathrm{Asp}_{249}, \mathrm{Lys}_{256}, \mathrm{Gln}_{357}, \mathrm{Pro}_{363}, \mathrm{Lys}_{455}, \mathrm{Thr}_{324}$, and $\mathrm{Arg}_{384}$ residues in CAT. Besides, TC toxicity was positively correlated with the ion bonds of $\mathrm{N}^{4}-\mathrm{Glu}_{252}$, but negatively correlated with the ion bonds of $\mathrm{N}^{4}-\mathrm{Asp}_{379}$. In conclusion, above interactions could be used as important indexes to 

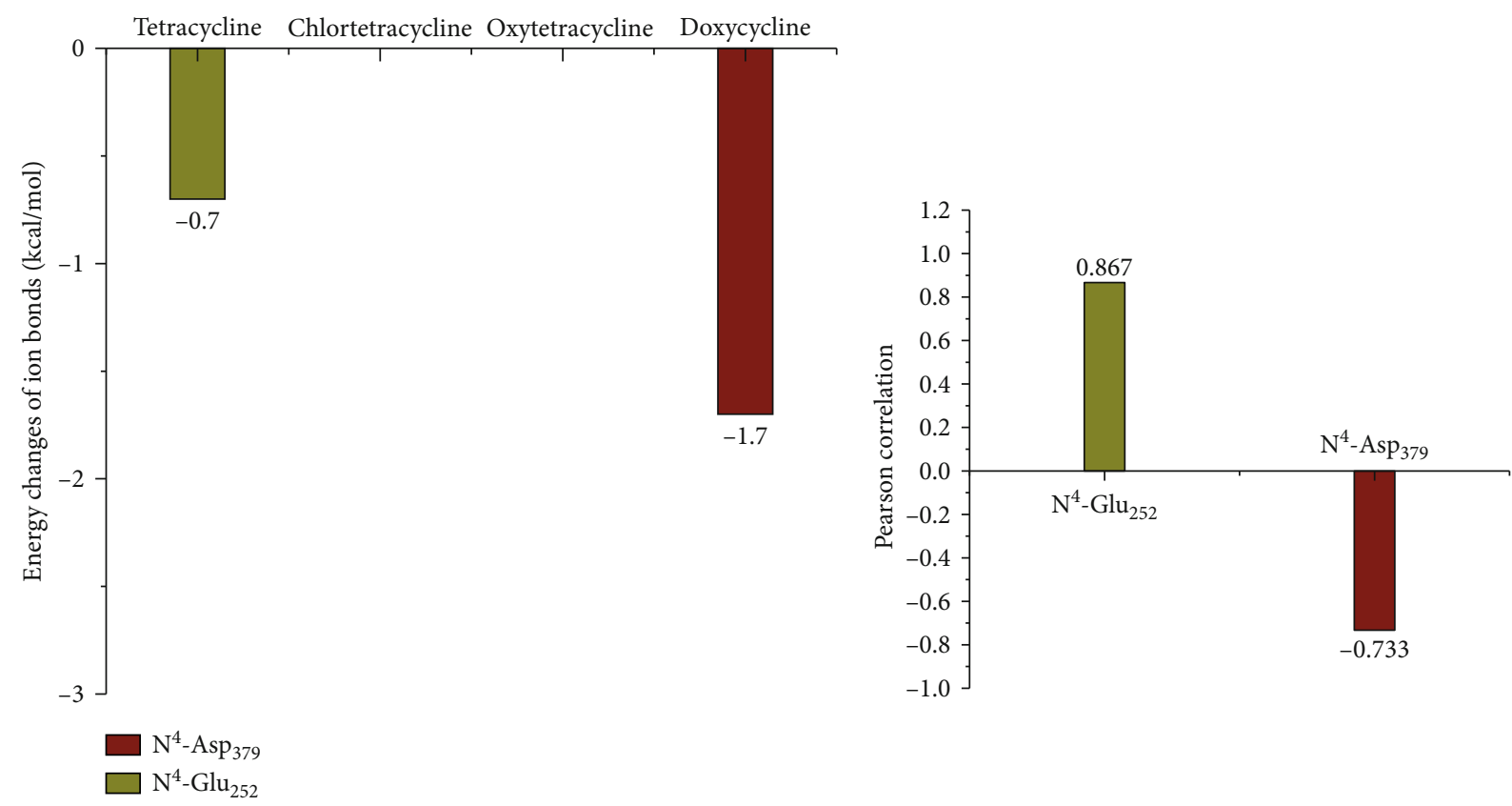

(a)

(b)

FIgURE 9: Molecular simulation information of the ion bonds for TC-CAT complexes: (a) energy changes of the ion bonds for TC-CAT complexes; (b) the correlation between TC toxicity and ion bonds.

evaluate the inhibition mechanism of TCs on the CAT activity. The regulation of TC toxicity could be achieved by weakening or strengthening the hydrogen bonds and ion bonds for some key interaction sites.

\section{Data Availability}

The datasets, codes, and corresponding results are available at https://figshare.com/articles/Catalase_correlation_zip/ 12398684 .

\section{Conflicts of Interest}

The authors declare that there are no conflicts of interest.

\section{Authors' Contributions}

Luyao Ren and Qian Wang contributed equally to this work.

\section{Acknowledgments}

This work is supported by National Natural Science Foundation of China (21876103).

\section{Supplementary Materials}

Supplementary information. (Supplementary Materials)

\section{References}

[1] M. L. Hanson, C. W. Knapp, and D. W. Graham, "Field assessment of oxytetracycline exposure to the freshwater macro- phytes Egeria densa planch. and Ceratophyllum demersum L," Environmental Pollution, vol. 141, no. 3, pp. 434-442, 2006.

[2] W. D. Kong, Y. G. Zhu, Y. C. Liang, J. Zhang, F. A. Smith, and M. Yang, "Uptake of oxytetracycline and its phytotoxicity to alfalfa (Medicago sativa L.)," Environmental Pollution, vol. 147, no. 1, pp. 187-193, 2007.

[3] S. Brillantes, V. Tanasomwang, S. Thongrod, and N. Dachanantawitaya, "Oxytetracycline residues in giant freshwater prawn (Macrobrachium rosenbergii)," Journal of Agricultural \& Food Chemistry, vol. 49, no. 10, pp. 49954999, 2001.

[4] A. Pena, C. M. Lino, R. Alonso, and D. Barceló, "Determination of tetracycline antibiotic residues in edible swine tissues by liquid chromatography with spectrofluorometric detection and confirmation by mass spectrometry," Journal of Agricultural \& Food Chemistry, vol. 55, no. 13, pp. 4973-4979, 2007.

[5] G. Rigos, I. Nengas, M. Alexis, and G. M. Troisi, "Potential drug (oxytetracycline and oxolinic acid) pollution from Mediterranean sparid fish farms," Aquatic Toxicology, vol. 69, no. 3, pp. 281-288, 2004.

[6] L. Ji, W. Chen, L. Duan, and D. Zhu, "Mechanisms for strong adsorption of tetracycline to carbon nanotubes: a comparative study using activated carbon and graphite as adsorbents," Environmental Science \& Technology, vol. 43, no. 7, pp. 2322-2327, 2009.

[7] R. Hirsch, T. Ternes, K. Haberer, and K. L. Kratz, "Occurrence of antibiotics in the aquatic environment," Science of the Total Environment, vol. 225, no. 1-2, pp. 109-118, 1999.

[8] J. Q. Zhang and Y. H. Dong, "Effect of low-molecular-weight organic acids on the adsorption of norfloxacin in typical variable charge soils of China," Journal of Hazardous Materials, vol. 151, no. 2-3, pp. 833-839, 2008. 
[9] A. Petchiappan and D. Chatterji, "Antibiotic resistance: current perspectives," ACS Omega, vol. 2, no. 10, pp. 74007409, 2017.

[10] S. E. Jørgensen and B. Hallingsørensen, "Drugs in the environment," Chemosphere, vol. 40, no. 7, pp. 691-699, 2000.

[11] S. R. Wegst-Uhrich, D. A. G. Navarro, L. Zimmerman, and D. S. Aga, "Assessing antibiotic sorption in soil: a literature review and new case studies on sulfonamides and macrolides," Chemistry Central Journal, vol. 8, no. 1, p. 5, 2014.

[12] P. H. Chang, Z. Li, T. L. Yu et al., "Sorptive removal of tetracycline from water by palygorskite," Journal of Hazardous Materials, vol. 165, no. 1-3, pp. 148-155, 2009.

[13] S. J. Aitcheson, J. Arnett, K. R. Murray, and J. Zhang, "Removal of aquaculture therapeutants by carbon adsorption," Aquaculture, vol. 183, no. 3-4, pp. 269-284, 2000.

[14] S. J. Aitcheson, "Removal of aquaculture therapeutants by carbon adsorption," Aquaculture, vol. 192, no. 2-4, pp. 249-264, 2001.

[15] A. Göbel, A. Thomsen, C. S. McArdell, A. Joss, and W. Giger, "Occurrence and sorption behavior of sulfonamides, macrolides, and trimethoprim in activated sludge treatment," Environmental Science \& Technology, vol. 39, no. 11, pp. 3981-3989, 2005.

[16] A. Gobel, C. McArdell, A. Joss, H. Siegrist, and W. Giger, "Fate of sulfonamides, macrolides, and trimethoprim in different wastewater treatment technologies," Science of the Total Environment, vol. 372, no. 2-3, pp. 361-371, 2007.

[17] R. H. Lindberg, P. Wennberg, M. I. Johansson, M. Tysklind, and B. A. V. Andersson, "Screening of human antibiotic substances and determination of weekly mass flows in five sewage treatment plants in Sweden," Environmental Science and Technology, vol. 39, no. 10, pp. 3421-3429, 2005.

[18] T. A. Ternes, A. Joss, and H. Siegrist, "Peer reviewed: scrutinizing pharmaceuticals and personal care products in wastewater treatment," Environmental Science \& Technology, vol. 38, no. 20, pp. 392A-399A, 2004.

[19] P. Montavon, K. R. Kukic, and K. Bortlik, "A simple method to measure effective catalase activities: optimization, validation, and application in green coffee," Analytical Biochemistry, vol. 360, no. 2, pp. 207-215, 2007.

[20] X. Zhang and J. Jin, "Binding analysis of pazufloxacin mesilate to catalase using spectroscopic methods," Journal of Molecular Structure, vol. 882, no. 1-3, pp. 96-100, 2008.

[21] V. V. Barynin, M. M. Whittaker, S. V. Antonyuk et al., "Crystal structure of manganese catalase from Lactobacillus plantarum," Structure, vol. 9, no. 8, pp. 725-738, 2001.

[22] F. Jing, O. Ju, J. Qiu, and K. Chen, "Regularity for Change of Urease and Catalase in Wastewater Treatment with Activated Sludge Process," in International Conference on Bioinformatics and Biomedical Engineering, 2010.

[23] L. F. Yang, Q. Zeng, H. B. Li, and J. J. Yan, "Determination of soil catalase activity by ultraviolet spectrophotometry," Chinese Journal of Soil Science, vol. 42, no. 1, pp. 207-210, 2011.

[24] C. Qin, A. MengxiaXie, and Y. Liu, "Characterization of the myricetin-human serum albumin complex by spectroscopic and molecular modeling approaches," Biomacromolecules, vol. 8, no. 7, pp. 2182-2189, 2007.
[25] C. J. Zhu and B. W. Yi, "Acquisition of free chemical and chemical information resources on the Internet," Journal of Jishou University (Natural Science Edition), vol. 32, no. 2, pp. 124-128, 2011.

[26] S. Soares, N. Mateus, and V. de Freitas, "Interaction of different polyphenols with bovine serum albumin (BSA) and human salivary $\alpha$-amylase (HSA) by fluorescence quenching," Journal of Agricultural and Food Chemistry, vol. 55, no. 16, pp. 6726-6735, 2007. 